\title{
Association between respiratory and heart rate fluctuations and death occurrence in dying cancer patients: Continuous measurement with a non-wearable monitor
}

\author{
Sakiko Fukui ( $\nabla$ fukuisakiko.chn@tmd.ac.jp) \\ Tokyo Medical and Dental University: Tokyo Ika Shika Daigaku https://orcid.org/0000-0002-5424-3521 \\ Kasumi lkuta \\ Osaka University: Osaka Daigaku \\ Isseki Maeda \\ Senri Chuo Hospital \\ Satoshi Hattori \\ Osaka University: Osaka Daigaku \\ Yutaka Hatano \\ Daini Kyoritsu Hospital \\ Miyae Yamakawa \\ Osaka University: Osaka Daigaku \\ Momoe Utsumi \\ Osaka University: Osaka Daigaku \\ Yoko Higami \\ Osaka Medical College: Osaka Ika Daigaku \\ Haruka Tanaka \\ Nagoya University: Nagoya Daigaku \\ Akari Higuchi \\ Kyoto University: Kyoto Daigaku
}

\section{Research Article}

Keywords: respiratory rate, heart rate, death, cancer, monitoring device, non-wearable

Posted Date: March 16th, 2021

DOI: https://doi.org/10.21203/rs.3.rs-144355/v2

License: (c) (i) This work is licensed under a Creative Commons Attribution 4.0 International License. Read Full License

Version of Record: A version of this preprint was published at Supportive Care in Cancer on July 7th, 2021. See the published version at https://doi.org/10.1007/s00520-021-06346-y. 


\section{Abstract \\ Background}

The present study aimed to explore the association between impending death and continual changes in respiratory and heart rates measured by a non-wearable monitor every minute for the final 2 weeks of dying cancer patients.

\section{Methods}

In this longitudinal study, we enrolled patients in a palliative-care-unit and continuously measured their respiratory/heart rates by a monitor, capturing their other vital signs and clinical status from medical records.

\section{Result}

A dataset was created with 240 patient-days from every minute data to death (345,600 data) among 24 patients for 3-14 days to death. We analyzed this 240 patient-day data. After confirming the associations between the value of death day $(n=24)$ or other days (2-14 days before death, $n=216)$ and the mean, maximum, minimum, and variance of respiratory and heart rates every 24 hours by univariate analyses, we conducted a repeated measures logistic regression analysis using a generalized estimating equation. Finally, the maximum respiratory rate and mean heart rate were significantly associated with death at 24 , 48 , and 72 hours later, other than the respiratory rate of the last 24 hours.

\section{Conclusion}

The maximum respiratory rate and mean heart rate measured every minute by a monitor can warn imminent death during the last days of life among dying patients. Our findings can help for family caregivers and care staff to aware imminent death among dying patients at home or in facilities, in collaboration with palliative care professionals.

\section{Introduction}

The number of patients suffering from cancer and who have died from it has increased significantly in the last few decades worldwide. ${ }^{1}$ The deaths are especially high in patients who are at home or in facilities owing to the aging society all over the world. Therefore, if we can aware imminent death by using a monitoring device, it will warn the family members and care staff of the occurrence of death, in collaboration with palliative care professionals. ${ }^{2}$

Additionally, as Japan's rapidly declining population will become a major social issue in the near future, ${ }^{3}$ utilizing technology to provide qualified care may be a solution for the declining number of healthcare professionals.

Prognostic tools, such as the Palliative Performance Scale, Palliative Prognostic Index, and Glasgow Prognostic Score, have recently been developed for the prognosis of cancer patients, as reviews have summarized. ${ }^{4,5}$ These tools capture a wide range of clinical factors that, together with professional clinical assessment, can help make accurate predictions. In addition, although several studies have examined the association between vital signs and prognosis prediction, ${ }^{6-11}$ these studies recorded the vital signs of cancer patients 1-2 times a day or only at the time of hospital admission. To the best of our knowledge, no study has investigated the prognosis prediction accuracy by focusing on continuous measurement of respiratory and heart rates using a non-wearable monitor in dying cancer patients during the last days of life, excepting two studies for non-cancer patients. ${ }^{12,13}$

In recent years, reviews that examine the association between changes in vital signs and patient outcomes by utilizing technology have been published. These include palliative cancer patients to monitor early changes in their conditions, ${ }^{14}$ cancer survivors to summarize the effectiveness of behavioral trials, ${ }^{15}$ and non-cancer patients to detect early deteriorations. ${ }^{16-18}$ These $^{2}$ 
reviews indicate that most recent studies used wearable monitors for non-dying patients. However, some studies reported that wearable monitors are invasive for dying patients and they are heavily burdened by these monitors. ${ }^{14,19,20}$

In contrast, a sheet-type device that can ensure the reliability and validity of vital sign measurement using a non-wearable monitor has recently been reported. ${ }^{21,22}$ If this non-wearable monitor can continuously measure vital signs without imposing a burden on the patient prior to death, it may be possible to assess the patient's condition in detail. Additionally, if we confirmed the association between continuously measured respiratory and heart rates assessed with a non-wearable monitor and the determination of prognosis, it may be more advantageous than previous clinical practices which did not monitor the vital signs continuously.

Therefore, this study aimed to explore the association between monitoring continual changes in respiratory and heart rates and impending death in the final 2 weeks of life of cancer patients. We, thus, investigated whether changes in respiratory and heart rates are associated with death within the following three days and also calculated the probability of death in the following three days based on these changes.

\section{Materials And Methods}

\section{Setting and Subjects}

This study was conducted in a 51-bed palliative care unit in Japan from April 2018 to October 2019. Palliative care physicians enrolled patients with an estimated life expectancy of a few weeks, as determined by clinical judgment and prognostic models, such as the Palliative Prognostic Index ${ }^{23}$ and Palliative Prognosis Score. ${ }^{24}$ Patients were included in this study if their estimated survival period till death was 3 days or more.

\section{Dependent variable (outcome)}

The outcome variable was the occurrence of death every 24 hours. Death occurrence was defined as the patient's medical record stating a death diagnosis by a doctor in charge. Moreover, one day prior to death was defined as the time of death to $24 \mathrm{~h}$ before death.

\section{Main independent variables measured by a monitor}

This study used a non-wearable actigraphy monitor (Nemuri SCAN, Paramount Bed Co. Ltd., Tokyo, Japan) containing a highly sensitive pressure sensor. ${ }^{25}$ The device was $28.6 \mathrm{~cm}$ long, $77 \mathrm{~cm}$ wide, and $2.5 \mathrm{~cm}$ thick (Figure 1). The sensing monitor was placed under a mattress. This monitor measured respiratory rate, heart rate, and the amount of activity per minute and calculated sleep, arousal, and out-of-bed status using these data. The reliability and validity of the Nemuri SCAN are guaranteed (Figure1). ${ }^{21,22}$

In this study, we focused on two vital signs, respiratory rate and heart rate, because these data were automatically gathered every minute by the Nemuri SCAN device, and created a dataset of the mean, maximum, minimum, and variance of respiratory rate and heart rate every 24 hours up to death for each patient, each calculated from monitoring data every minute.

We examined the mean, maximum, minimum, and variance values of respiratory rate and heart rate measured by monitoring on the day of death $(n=24)$ and other days $(2-14$ days before death, $n=216)$.

\section{Other independent variables extracted by medical records}

Age, sex, and primary cancer site were recorded as patient demographic characteristics.

We also collected the following independent variables that were evaluated every 24 hours up to death, which were extracted from the patient's medical records, referring to a previous study ${ }^{23}$ : (1) nurse-measured vital signs were collected, including respiratory rate, heart rate, temperature, systolic blood pressure, and diastolic blood pressure, and these vital signs were used as continuous values; moreover, nurses measured vital signs twice a day, and we recorded the mean, maximum, and minimum for that day; (2) 
subjective symptoms comprising six items: pain, dyspnea, malaise, restlessness, nausea, and dry mouth; (3) objective symptoms comprising eight items: painful expression, cough, sputum, cold limbs, edema, oral fluid intake, oral food intake, and delirium; and (4) drug use that was divided into opioids, non-opioids, hypnotics, and artificial hydration.

Two nurses (IK and SF) read each medical record and extracted clinical data separately. Thereafter, the two confirmed the validity of the data obtained.

\section{Statistical analyses}

We created a dataset of (i) outcomes (from death-day to 2-14 days before death per patient, totaling 240 patient-day data), (ii) data measured by a monitor (mean, variance, maximum, and minimum respiratory rate and heart rate), and (iii) patient demographic characteristics, symptoms, and drug use from medical records. Symptoms and drug use were integrated in chronological order every $24 \mathrm{~h}$ to death.

First, we calculated the descriptive statistics for the patient demographic characteristics, nurse-measured vital signs, subjective symptoms, objective symptoms, and drug use to clarify the background and clinical status of the patients.

Next, by univariate analyses using t-tests, we examined the association between the value of death day $(n=24)$ and the value of other days (2-14 days before death, $n=216)$ for the mean, maximum, minimum, and variance of respiratory rate and heart rate measured by the monitor.

Finally, we examined the association between respiratory and heart rates and death using repeated measures logistic regression analysis. To this end, we prepared three types of binary outcomes for each day: death occurrence within 24 hours, 48 hours, and 72 hours. Several explanatory variables representing the within-day level/variation of the respiratory and heart rates were prepared, including the mean, maximum, minimum, and variance of respiratory rate and heart rate. Note that each outcome was defined every 24 hours from the date of death, and each patient had multiple observations. Accounting for within-patient correlation among repeatedly observed outcomes, we performed a repeated measures logistic regression analysis with the generalized estimating equation (GEE). ${ }^{26}$ In making a valid statistical inference, we utilized the robust sandwich variance with the working independent correlation. According to the fitted logistic model, we calculated the predicted probability of death within the next 3 days (72 hours) based on the respiratory and heart rates for each of the 24 subjects.

All analyses were performed using the Statistical Analysis System (SAS) version 9.4 (SAS, Institute Inc., Cary, NC, USA), and $\mathrm{p}<0.05$ was considered significant.

\section{Research ethics and patient consent}

This study was conducted with the approval of the Ethics Review Committee of Intervention Studies and Observational Research, Osaka University Hospital (approval number: 1741110). After explaining the study protocol to eligible patients, written informed consent was obtained from each patient. Participation in the study was voluntary, and patients were informed that all data would be anonymous and their privacy and personal information would be protected. If a patient did not have sufficient mental capacity to decide on study participation, written consent was obtained from the patient's family/proxy. All methods were performed in accordance with Di-CHiLD project guideline, which is the Osaka University and Daikin Industries collaborative study.

\section{Results}

\section{Subjects}

In total, 30 patients were registered in this research project for the study duration. Of these, four patients were excluded owing to one or more days of missing data from the monitor from device installation to death, and two patients were excluded because they died less than 3 days from device installation. The remaining 24 patients were included in the analysis. We used a total of 240 patient-day data every 24 hours from a total of 1440 per minute data (60 minutes $\times 24$ hours a day) from 24 dying patients. 
There were no adverse events due to the use of the non-wearable device, and all 24 patients completed the monitoring procedures until death.

Patient demographic characteristics are summarized in Table 1. The mean age of participating patients was $76.7 \pm 11.1$ years, and there were 14 men and 10 women. The digestive tract was the most frequent primary cancer site $(n=10)$.

\section{Patient vital signs, symptoms, and drug use per 24 hours from 1-14 days to death}

Table 2 shows the trajectory of patient vital signs, symptoms, and drug use per 24 hours from 1 to 14 days to death. We typically chose the data from $1,2,3,4,7,10$, and 14 days to death.

Comparing respiratory rate and heart rate measured by the monitor and measured by nurses from medical records, the maximums and minimums were determined to be different, whereas the means were not significantly different. Additionally, we presented the other vital signs, symptoms, and drug use, which were measured by nurses 2 times per day, to show the patient clinical status for 2 weeks before death.

\section{Association between respiratory rate and heart rate and death within 24 hours, 48 hours, and 72 hours}

Table 3 shows the association between respiratory rate and heart rate measured by the monitor of death day and the value of other days (2-14 days before death) for the mean, variance, maximum, and minimum for day 1 (0-24 hours to death), day 2 (24-48 hours to death), day 3 (48-72 hours to death), and Day 4 (72-96 hours to death). Considering the patients' respiratory rates, several maximum values were shown to be significantly different between the day of death and those on other days, while heart rate showed that several mean values were similar. Therefore, after confirming the associations between the value of death day $(n=24)$ or other days (2-14 days before death, $n=216)$ and the mean, maximum, minimum, and variance of every 24 -hour respiratory and heart rates by univariate analyses, we chose the maximum respiratory rate and mean heart rate to investigate the association with death prediction. Table 4 shows the association between maximum respiratory rate/mean heart rate and impeding death within the following 24 hours, 48 hours, and 72 hours by repeated measures logistic regression analysis using a GEE.

With the exception of respiratory rate in the last 24 hours, the maximum respiratory rate and mean heart rate were significantly associated with impeding death within the following $0-24$ hours, $0-48$ hours, and $0-72$ hours (odds ratio [95\% confidence interval], $p=1.04$ [0.98-1.10], $p=0.17 ; 1.08$ [1.02-1.15], $p=0.008 ; 1.10$ [1.01-1.12], $p=0.03 ; 1.02$ [1.01-1.04], $p=0.02 ; 1.03$ [1.011.05], $p=0.0005 ; 1.03$ [1.01-1.05], $p=0.001$, respectively). For example, for clinical interpretation, the odds ratio was 1.08 between respiratory rate and death occurrence within 48 hours. When 5 accounts for an increase in the maximum respiratory rate per day, the possibility of death occurrence within 48 hours means 1.47 times increase ( $47 \%$ risk increment).

We have also included every 24-hour change in respiratory and heart rates among the 24 dying patients for $3-14$ days prior to death (Appendix). The appendix shows that the value of the mean heart rate tends to increase gradually toward death, whereas the value of the maximum respiratory rate among some patients tends to decrease approximately 2-4 days before death. Regarding the probability of death occurrence calculated by these two variables, some people gradually increased to a final rate of approximately $60 \%-80 \%$ to death day, while some remained at approximately $30 \%$.

\section{Discussion}

This study showed that respiratory/heart rate fluctuations accurately measured using a non-wearable monitor were significantly associated with a dying cancer patient's death during their final days of life. This finding suggests that continuous measurement of respiratory/heart rates by a non-wearable monitor can warn about death occurrence within several days of the death-day with some accuracy. It will be helpful for family members and care staff to aware imminent death among dying patients at home or in facilities, even in the absence of healthcare professionals at all times.

One of the key findings of this study was the clarification in the change in maximum, minimum, mean, and variance of respiratory and heart rates among dying cancer patients for 2 weeks before death, which were captured by a non-wearable 
monitor every minute. The maximum and minimum values measured by the monitor were significantly different from those routinely measured by nurses twice a day. In clinical practice, the vital signs of dying patients are unstable, such as a sudden decrease in respiratory rate per minute caused by respiratory disorders/apnea syndrome ${ }^{27,28}$ and a sudden increase in respiratory rate caused by acidosis. ${ }^{29}$ This study showed that the use of non-wearable monitors can accurately capture such changes in dying patients, thus the maximum and minimum values are different from those measured by nurses and showed a wide range.

The second important finding of this study was that the changes in maximum respiratory rate and mean heart rate could become warning signs of imminent death in the last 2 weeks of life among dying patients. This is because the maximum respiratory rate and mean heart rate were significantly associated with the occurrence of death within 72 hours. Previous studies that have examined the association between vital signs and prognosis captured vital signs by medical records just once or twice a day or only used the data from hospital admission. ${ }^{7-11}$ In addition, no study has investigated the association between death occurrence and continuous measurement of respiratory/heart rates using a non-wearable monitor in dying cancer patients during the last days of life. A previous study showed a statistically significant increase in respiratory rate for the final days before death, ${ }^{30}$ while another study reported no statistically significant increase. ${ }^{8}$ This may be attributed to the roughness of data due to the low measurement frequency. In contrast to these previous findings, this study was able to continuously assess respiratory rate and heart rate using a monitor. Therefore, the results of this study suggest that two vital signs (respiratory rate and heart rate) measured by a monitor can warn about the imminent death of dying cancer patients in their last days with some accuracy, without considering the patient's clinical situation, such as other vital signs (blood pressure, oxygen saturation, and temperature) and symptoms and drug use, captured from medical records widely. Additionally, the mean value of heart rate measured by the monitor did not significantly deviate from the nurse's measurement, but the maximum/minimum of those deviated considerably between them. These deviations may be a region where the nurse could not observe (such as time zone and temporary change of patient status). This study suggests that continuous clinical observations of the maximum respiratory rate may be important for prognosis. We aim to continue to investigate the pathological conditions of dying cancer patients through measurements using such monitoring devices.

A third important result of this study is the clarification of the percentage of the probability of death within the following 72 hours using the maximum respiratory rate and mean heart rate. Although the percentage of prognosis due to these 2 variables before death varies individually and greatly ranged from $20 \%$ to $80 \%$ among patients, this study showed that the maximum respiratory rate and mean heart rate in some patients increased the probability of death within the next 72 hours. Therefore, we would like to increase the number of subjects to improve this accuracy in the future.

A recent review describing the current use of wearable monitors in oncology trials, ${ }^{15}$ proposed the importance of the potential use of wearable monitors to predict clinical outcomes, such as survival. Another recent review that summarized the ability of vital sign trends to predict clinical deterioration in patients with acute illness indicated that vital signs (i.e., respiratory rate, oxygen saturation, pulse, blood pressure, and temperature) are essential for early detection and timely intervention for preventive outcomes. ${ }^{30}$ Simultaneously, they also pointed out that several studies captured vital signs from medical records and that the best monitoring system is still unclear. ${ }^{17}$ Considering these studies, using a non-wearable noninvasive monitor to estimate imminent death of dying patients with some accuracy is considered beneficial. These may have great potential to contribute to future prognostication in advanced cancer, such as at home or in care facilities, in the absence of palliative care professionals at all times.

This study has several limitations. First, the sample size of this study was small, and because of the small sample size, it may not be possible to consider each patient's clinical status, such as symptoms and drug use, when considering their prognosis. However, without adjusting for these situations, this study showed that the maximum respiratory rate and mean heart rate of dying cancer patients may be able to predict the possibility of death within the subsequent 72 hours. Second, the patients were from a single palliative unit, and monitoring devices used in this study could not measure the patients' vital signs outside the patients' beds. 
If we are able to aware imminent death of dying cancer patients by measuring vital signs using a non-wearable device with some accuracy, at-home monitoring with few medical professionals will be possible in the future. Additionally, this could lead to the prevention of solitary death in the aging society worldwide, the relief of family's grief, and the provision of appropriate symptom management by healthcare professionals for patients who cannot express distress close to death, thus contributing to the improvement of their quality of life. In future, we plan to increase the number of subjects and take into consideration the symptoms and drug use of the subjects with the aim of more accurately predicting the prognosis of dying cancer patients.

\section{References}

1. Bray F, Ferlay J, Soerjomataram I et al. Global cancer statistics 2018. CA Cancer J Clin 2018;68:394-424.

2. Fukui S, Morita T, Yoshiuchi K. Development of a clinical tool to predict home death of a discharged cancer patient in Japan: a case-control study. Int J Behav Med 2017;24:584-92.

3. Ministry of Economy, Trade, And Industry. Economic and social up to 2050 Structural changes and policy issues. 2020. Accessed 6 January 2021 https://www.meti.go.jp/shingikai/sankoshin/2050_keizai/pdf/001_04_00.pdf

4. Simmons CPL, McMillan DC, McWilliams K et al. Prognostic tools in patients with advanced cancer: a systematic review. J Pain Symptom Manage 2017;53:962-70.

5. Hui D, Paiva CE, Del Fabbro EG et al. Prognostication in advanced cancer: update and directions for future research. Support Care Cancer 2019;27:1973-84.

6. Hui D, Shamieh O, Paiva CE et al. Minimal clinically important differences in the Edmonton Symptom Assessment Scale in cancer patients: A prospective, multicenter study. Cancer 2015;121:3027-35.

7. Chen YT, Ho CT, Hsu HS et al. Objective palliative prognostic score among patients with advanced cancer. J Pain Symptom Manage 2015;49:690-6.

8. Bruera S, Chisholm G, Santos RD et al. Variations in vital signs in the last days of life in patients with advanced cancer. J Pain Symptom Manage 2013;48:510-17.

9. Hwang IC, Ahn HY, Park SM et al. Clinical changes in terminally ill cancer patients and death within $48 \mathrm{~h}$ : when should we refer patients to a separate room? Support Care Cancer 2013;21:835-40.

10. Brabrand $\mathrm{M}$, Knudsen T, Hallas $\mathrm{J}$ et al. The PARIS score can reliably predict 7-day all-cause mortality for both acute medical and surgical patients: an international validation study. Int J Med 2018;111:721-25.

11. Hamano J, Takeuchi A, Yamaguchi T et al. A combination of routine laboratory findings and vital signs can predict survival of advanced cancer patients without physician evaluation: a fractional polynomial model. Eur J Cancer 2018;105:50-60.

12. Matsunami K, Tomita K, Touge H, et al. Physical Signs and Clinical Findings Before Death in III Elderly Patients. Am J Hosp Palliat Care 2018;35(4):712-717.

13. Hosoi T, Ozone S, Hamano J. Variations in vital signs at the end of life in non-cancer patients: a retrospective study. Ann Palliat Med 2020;9(5):2678-2683.

14. Pavic $\mathrm{M}$, Klaas $\mathrm{V}$, Theile $\mathrm{G}$ et al. Mobile health technologies for continuous monitoring of cancer patients in palliative care aiming to predict health status deterioration: a feasibility study. J Palliat Med 2020;23:678-85.

15. Gresham G, Schrack J, Gresham LM et al. Wearable activity monitors in oncology trials: Current use of an emerging technology. Contemp Clin Trials 2018;64:13-21.

16. Liu L, Stroulia E, Nikolaidis I et al. Smart homes and home health monitoring technologies for older adults: A systematic review. Int J Med Inform 2016;91:44-59.

17. Brekke IJ, Puntervoll LH, Pedersen PB et al. The value of vital sign trends in predicting and monitoring clinical deterioration: A systematic review. PLoS One 2019;15;14(1):e0210875.

18. Gokalp H, Folter J, Verma $\mathrm{V}$ et al. Integrated telehealth and telecare for monitoring frail elderly with chronic disease. Telemed J E Health 2018;24:940-57.

19. Cox A, Illsley M, Knibb W et al. The acceptability of e-technology to monitor and assess patient symptoms following palliative radiotherapy for lung cancer. Palliat Med 2011;25:675-81.

Page $7 / 12$ 
20. Ambrosino N, Vitacca M, Dreher M et al. Tele-monitoring of ventilator-dependent patients: a European Respiratory Society Statement. Eur Respir J 2016;48:648-63.

21. Kogure T, Kobayashi M, Okawa T et al. Validation of a sheet-shaped body vibrometer for screening of obstructive sleep apnea. Drug Discov Ther 2017;11:126-32.

22. Kogure T, Ebata T. Activity during sleep measured by a sheet-shaped body vibrometer and the severity of atopic dermatitis in adults: a comparison with wrist actigraphy. J Clin Sleep Med 2018;14:199-204.

23. Morita T, Tsunoda J. Contributing factors to physical symptoms in terminally-ill cancer patients. J Pain Symptom Manage 1999;18:338-346.

24. Downing M, Lau F, Lesperance M, Karlson N et al. Meta-analysis of survival prediction with Palliative Performance Scale. J Palliat Care 2007;23:245-52; discussion 252-4.

25. Kogure T, Shirakawa S, Shimokawa M et al. Automatic sleep/wake scoring from body motion in bed:validation of a newly developed sensor placed under a mattress. J Physiol Anthropol 2011;30:103-9.

26. Liang K, Zeger YL. Longitudinal data analysis using generalized linear models. Biometrika 1986;73:13-22.

27. Liu W, Luo M, Fang YY et al. Relationship between occurrence and progression of lung cancer and nocturnal intermittent hypoxia, apnea and daytime sleepiness. Curr Med Sci 2019;39:568-75.

28. Silberfarb PM, Hauri PJ, Oxman TE, Schnurr P. Assessment of sleep in patients with lung cancer and breast cancer. J Clin Oncol 1993;11:997-1004.

29. Davenport, Horace W. The ABC of Acid-Base Chemistry: The Elements of Physiological Blood-Gas Chemistry for Medical Students and Physicians. .Sixth ed.. Chicago: The University of Chicago Press; 1974.

30. Taylor P, Crouch S, Howell DA et al. Change in physiological variables in the last 2 weeks of life: An observational study of hospital in-patients with cancer. Palliat Med 2015;29:120-7.

\section{Tables}

Table 1 Patient demographic characteristics

\begin{tabular}{|c|c|}
\hline & Overall $(\mathrm{n}=24)$ \\
\hline & $\mathrm{n}(\%)$ or mean $\pm \mathrm{SD}^{*}$ \\
\hline \multicolumn{2}{|l|}{ Demographic } \\
\hline Sex: male & $14(58.3)$ \\
\hline Age & $76.7 \pm 11.1$ \\
\hline Height & $158.1 \pm 10.1$ \\
\hline Weight & $46.7 \pm 8.3$ \\
\hline Body Mass Index & $18.6 \pm 2.6$ \\
\hline \multicolumn{2}{|l|}{ Clinical } \\
\hline Primary cancer site: Digestive tract & $10(41.7)$ \\
\hline Pancreas & $5(20.8)$ \\
\hline Hepatobiliary & $2(8.3)$ \\
\hline Breast & $3(12.5)$ \\
\hline Gynecological & $2(8.3)$ \\
\hline Urological & $2(8.3)$ \\
\hline
\end{tabular}

*SD, standard deviation

Table 2. Patient vital signs and symptoms per 24 hours on days $1,2,3,4,7,10$, and 14 prior to death 


\begin{tabular}{|c|c|c|c|c|c|c|}
\hline $\begin{array}{c}\text { Day1 to } \\
\text { death } \\
\text { (0-24 hours } \\
\text { to death) }\end{array}$ & $\begin{array}{l}\text { Day2 to } \\
\text { death } \\
\text { (24 -48 } \\
\text { hours } \\
\text { to death) }\end{array}$ & $\begin{array}{c}\text { Day3 to death } \\
\text { (48-72 hours } \\
\text { to death) }\end{array}$ & $\begin{array}{c}\text { Day4 to death } \\
\text { (72-96 hours } \\
\text { to death) }\end{array}$ & $\begin{array}{l}\text { ay7 to death } \\
\text { (144-168 } \\
\text { hours } \\
\text { to death) }\end{array}$ & $\begin{array}{l}\text { Day10 to } \\
\text { death } \\
\text { (216-240 } \\
\text { hours } \\
\text { to death) }\end{array}$ & $\begin{array}{c}\text { Day14 to } \\
\text { death } \\
\text { (312-336 } \\
\text { hours } \\
\text { to death) }\end{array}$ \\
\hline $\mathrm{n}=24$ & $\mathrm{n}=24$ & $\mathrm{n}=24$ & $\mathrm{n}=22$ & $\mathrm{n}=19$ & $\mathrm{n}=14$ & $\mathrm{n}=9$ \\
\hline
\end{tabular}

Vital signs measured by monitor (from 1440 per minute data for 24 hours)

Respiratory rate (respirations per

\begin{tabular}{|c|c|c|c|c|c|c|c|}
\hline $\begin{array}{l}\text { minute, rpm) } \\
\text { Mean }\end{array}$ & $17.8 \pm 5.3$ & $15.2 \pm 4.0$ & $15.4 \pm 4.2$ & $14.9 \pm 4.1$ & $15.1 \pm 3.7$ & $14.2 \pm 3.2$ & $14.4 \pm 3.9$ \\
\hline Maximum & $30.9 \pm 5.6$ & $27.0 \pm 4.7$ & $26.1 \pm 5.8$ & $26.3 \pm 4.9$ & $23.9 \pm 4.3$ & $23.9 \pm 4.0$ & $25.8 \pm 5.1$ \\
\hline Minimum & $2.9 \pm 3.7$ & $5.5 \pm 4.0$ & $4.5 \pm 4.0$ & $4.3 \pm 4.1$ & $4.7 \pm 4.2$ & $3.3 \pm 3.9$ & $1.8 \pm 3.7$ \\
\hline Variance & $18.7 \pm 14.5$ & $7.2 \pm 4.2$ & $9.0 \pm 7.4$ & $10.3 \pm 11.2$ & $7.3 \pm 5.3$ & $7.1 \pm 4.8$ & $10.7 \pm 6.7$ \\
\hline \multicolumn{8}{|c|}{ Heart rate (beats per minute, bpm) } \\
\hline Mean & $92.6 \pm 17.4$ & $88.4 \pm 16.8$ & $88.1 \pm 19.1$ & $84.8 \pm 18.0$ & $81.8 \pm 15.7$ & $78.7 \pm 16.4$ & $76.7 \pm 12.8$ \\
\hline Maximum & $120.8 \pm 22.3$ & $110.0 \pm 18.1$ & $108.7 \pm 19.4$ & $106.6 \pm 19.3$ & $109.9 \pm 21.8$ & $113.7 \pm 23.4$ & $104.6 \pm 16.0$ \\
\hline Minimum & $44.7 \pm 8.2$ & $51.1 \pm 11.0$ & $51.5 \pm 12.2$ & $55.8 \pm 19.1$ & $53.1 \pm 14.0$ & $53.1 \pm 16.7$ & $47.4 \pm 8.9$ \\
\hline Variance & $187.1 \pm 220.8$ & $66.4 \pm 79.2$ & $49.5 \pm 44.0$ & $48.5 \pm 63.9$ & $61.2 \pm 80.0$ & $67.0 \pm 55.2$ & $77.0 \pm 69.4$ \\
\hline \multirow{2}{*}{\multicolumn{8}{|c|}{$\begin{array}{l}\text { Vital signs measured by nurse (from } \\
\text { two times' data a day) } \\
\text { Respiratory rate (rpm) }\end{array}$}} \\
\hline & & & & & & & \\
\hline Mean & $19.8 \pm 8.3$ & $18.0 \pm 7.9$ & $14.6 \pm 9.4$ & $18.0 \pm 7.6$ & $15.6 \pm 5.2$ & $18.0 \pm 5.6$ & $15.0 \pm 2.2$ \\
\hline Maximum & $21.6 \pm 8.5$ & $18.8 \pm 8.2$ & $15.3 \pm 9.3$ & $19.0 \pm 7.0$ & $16.4 \pm 5.0$ & $18.3 \pm 5.5$ & $15.7 \pm 3.8$ \\
\hline Minimum & $18.3 \pm 8.0$ & $17.3 \pm 8.0$ & $13.8 \pm 9.4$ & $17.0 \pm 8.4$ & $14.8 \pm 5.6$ & $17.7 \pm 5.7$ & $14.3 \pm 2.1$ \\
\hline \multicolumn{8}{|l|}{ Heart rate $(\mathrm{bpm})$} \\
\hline Mean & $92.9 \pm 19.3$ & $87.1 \pm 16.7$ & $88.2 \pm 19.5$ & $85.2 \pm 15.4$ & $85.4 \pm 14.4$ & $83.6 \pm 16.7$ & $80.6 \pm 14.7$ \\
\hline Maximum & $96.9 \pm 19.4$ & $89.2 \pm 17.8$ & $90.3 \pm 21.6$ & $87.2 \pm 16.3$ & $86.1 \pm 14.2$ & $85.4 \pm 18.2$ & $80.9 \pm 15.2$ \\
\hline Minimum & $89.8 \pm 21.0$ & $85.7 \pm 16.7$ & $86.5 \pm 18.2$ & $83.2 \pm 15.4$ & $84.8 \pm 14.8$ & $81.8 \pm 15.9$ & $80.3 \pm 14.2$ \\
\hline \multicolumn{8}{|l|}{ Temperature $\left({ }^{\circ} \mathrm{C}\right)$} \\
\hline Mean & $37.1 \pm 0.8$ & $36.9 \pm 0.4$ & $36.9 \pm 0.5$ & $36.9 \pm 0.6$ & $36.9 \pm 0.5$ & $36.7 \pm 0.4$ & $36.8 \pm 0.3$ \\
\hline Maximum & $37.3 \pm 0.8$ & $37.1 \pm 0.7$ & $37.1 \pm 0.8$ & $37.0 \pm 0.7$ & $37.1 \pm 0.7$ & $36.7 \pm 0.4$ & $37.0 \pm 0.5$ \\
\hline Minimum & $37.0 \pm 0.8$ & $36.8 \pm 0.4$ & $36.8 \pm 0.3$ & $36.8 \pm 0.6$ & $36.7 \pm 0.3$ & $36.7 \pm 0.4$ & $36.7 \pm 0.3$ \\
\hline \multicolumn{8}{|c|}{ Systolic blood pressure (mmHg) } \\
\hline Mean & $95.3 \pm 22.3$ & $100.0 \pm 18.5$ & $107.2 \pm 20.3$ & $107.4 \pm 19.0$ & $112.0 \pm 19.0$ & $111.0 \pm 22.1$ & $117.0 \pm 19.9$ \\
\hline Maximum & $99.2 \pm 22.1$ & $100.2 \pm 18.2$ & $110.0 \pm 18.7$ & $110.0 \pm 23.4$ & $113.1 \pm 18.9$ & $111.8 \pm 21.7$ & $117.1 \pm 19.8$ \\
\hline Minimum & $91.7 \pm 24.7$ & $99.8 \pm 18.9$ & $104.3 \pm 23.1$ & $105.3 \pm 18.7$ & $110.9 \pm 19.6$ & $110.2 \pm 22.7$ & $116.8 \pm 20.0$ \\
\hline \multicolumn{8}{|c|}{ Diastolic blood pressure (mmHg) } \\
\hline Mean & $62.6 \pm 14.3$ & $60.3 \pm 13.2$ & $65.6 \pm 12.9$ & $64.6 \pm 11.8$ & $63.9 \pm 13.0$ & $63.0 \pm 13.7$ & $62.6 \pm 7.4$ \\
\hline Maximum & $63.9 \pm 13.1$ & $60.5 \pm 13.3$ & $67.0 \pm 13.9$ & $66.8 \pm 13.9$ & $64.9 \pm 12.5$ & $64.2 \pm 13.6$ & $63.0 \pm 7.1$ \\
\hline Minimum & $61.1 \pm 15.7$ & $60.2 \pm 13.2$ & $64.2 \pm 12.6$ & $62.6 \pm 12.3$ & $62.9 \pm 13.9$ & $61.7 \pm 14.2$ & $62.1 \pm 7.9$ \\
\hline \multicolumn{8}{|l|}{ Subjective symptoms } \\
\hline Pain & $5(20.8)$ & $10(41.7)$ & $8(33.3)$ & $6(27.3)$ & $7(36.8)$ & $7(50.0)$ & $3(33.3)$ \\
\hline Dyspnea & $4(16.7)$ & $6(25.0)$ & $4(16.7)$ & $4(18.2)$ & $2(10.5)$ & $1(7.1)$ & $0(0)$ \\
\hline Malaise & $9(37.5)$ & $10(41.7)$ & $11(45.8)$ & $11(50.0)$ & $11(57.9)$ & $6(42.9)$ & $3(33.3)$ \\
\hline Restlessness & $7(29.2)$ & $6(25.0)$ & $7(29.2)$ & $3(13.6)$ & $3(15.8)$ & $0(0)$ & $0(0)$ \\
\hline Nausea & $1(4.2)$ & $1(4.2)$ & $0(0)$ & $0(0)$ & $0(0)$ & $0(0)$ & $0(0)$ \\
\hline Dry mouth & $2(8.3)$ & $3(12.5)$ & $3(12.5)$ & $3(13.6)$ & $1(5.3)$ & $1(7.1)$ & $0(0)$ \\
\hline \multicolumn{8}{|l|}{ Objective symptoms } \\
\hline Painful expression & $9(37.5)$ & $9(37.5)$ & $5(20.8)$ & $3(13.6)$ & $5(26.3)$ & $1(7.1)$ & $0(0)$ \\
\hline Cough & $2(8.3)$ & $1(4.2)$ & $2(8.3)$ & $2(9.1)$ & $1(5.3)$ & $1(7.1)$ & $0(0)$ \\
\hline Sputum & $5(20.8)$ & $5(20.8)$ & $2(8.3)$ & $2(9.1)$ & $1(5.3)$ & $2(14.3)$ & $0(0)$ \\
\hline Cold limbs & $16(66.7)$ & $7(29.2)$ & $4(16.7)$ & $1(4.6)$ & $2(10.5)$ & $0(0)$ & $0(0)$ \\
\hline Edema & $9(37.5)$ & $8(33.3)$ & $8(33.3)$ & $7(31.8)$ & $7(36.8)$ & $4(28.6)$ & $2(22.2)$ \\
\hline Oral fluid intake & $2(8.3)$ & $7(29.2)$ & $13(54.2)$ & $14(63.6)$ & $15(79.0)$ & $10(71.4)$ & $7(77.8)$ \\
\hline \multicolumn{8}{|l|}{ Use of Drugs } \\
\hline Opioids & $8(33.3)$ & $8(33.3)$ & $8(33.3)$ & $9(40.9)$ & $7(36.8)$ & $6(42.9)$ & $1(11.1)$ \\
\hline Non-opioids & $3(12.5)$ & $7(29.2)$ & $7(29.2)$ & $6(27.3)$ & $4(21.1)$ & $4(28.6)$ & $1(11.1)$ \\
\hline Hypnotics & $1(4.2)$ & $0(0)$ & $1(4.2)$ & $2(9.1)$ & $4(21.1)$ & $4(28.6)$ & $1(11.1)$ \\
\hline Artificial hydration & $3(12.5)$ & $3(12.5)$ & $4(16.7)$ & $4(18.2)$ & $5(26.3)$ & $3(21.4)$ & $2(22.2)$ \\
\hline
\end{tabular}

*SD, standard deviation 
Table 3. Comparison of patient vital signs measured by monitor between death day (Day1, $\mathrm{n}=24)$ and $2-14$ days before death $(\mathrm{n}=216 *$ ) $* *$

$\begin{array}{cccc}\text { Day1 to } & \text { Day2 to } & \text { Day3 to death } & \text { Day4 to death } \\ \text { death } & \text { death } & (48-72 \text { hours } & \text { (72-96 hours } \\ (0-24 \text { hours } & (24-48 & \text { to death) } & \text { to death) }\end{array}$

to death) hours

to death) to death)

\begin{tabular}{|c|c|c|c|c|c|c|c|c|c|c|c|c|}
\hline & to death) & & & $\begin{array}{l}\text { hours } \\
\text { to death) }\end{array}$ & & & & & & & & \\
\hline & $\begin{array}{c}\mathrm{n}=240 \\
\text { mean } \pm \mathrm{SD} * * *\end{array}$ & $\begin{array}{c}\mathrm{t}- \\
\text { value }\end{array}$ & $\mathrm{p}$-value & $\begin{array}{c}\mathrm{n}=216^{\mathrm{a}} \\
\text { mean } \pm \mathrm{SD}\end{array}$ & $\begin{array}{c}\mathrm{t}- \\
\text { value }\end{array}$ & $\begin{array}{c}\mathrm{p}- \\
\text { value }\end{array}$ & $\begin{array}{l}\mathrm{n}=192^{\mathrm{b}} \\
\text { mean } \pm \mathrm{SD}\end{array}$ & $\begin{array}{c}\mathrm{t}- \\
\text { value }\end{array}$ & $\begin{array}{c}\mathrm{p}- \\
\text { value }\end{array}$ & $\begin{array}{c}\mathrm{n}=168^{\mathrm{c}} \\
\text { mean } \pm \mathrm{SD}\end{array}$ & $\begin{array}{c}\mathrm{t}- \\
\text { value }\end{array}$ & $\begin{array}{c}\mathrm{p}- \\
\text { value }\end{array}$ \\
\hline $\begin{array}{l}\text { Vital signs measured } \\
\text { Respiratory rate (per } \\
\text { minute) } \\
\quad \text { Mean } \\
\text { day }\end{array}$ & y monitor (fro & n 1440 & per minu & te data for 24 & hours) & 0.56 & $15.4 \pm 4.2$ & -0.99 & 0.33 & $14.9 \pm 4.1$ & -0.34 & 0.73 \\
\hline $\begin{array}{l}\text { 2-14 days } \\
\text { before death }\end{array}$ & $14.8 \pm 3.8$ & & & $14.7 \pm 3.7$ & & & $14.6 \pm 3.7$ & & & $14.6 \pm 3.6$ & & \\
\hline $\begin{array}{l}\text { Maximum } \\
\text { Death day }\end{array}$ & $30.9 \pm 5.6$ & -6.13 & $<0.001$ & $27.0 \pm 4.7$ & -2.41 & 0.02 & $26.1 \pm 5.8$ & -1.30 & 0.21 & $26.3 \pm 4.9$ & -2.16 & 0.03 \\
\hline $\begin{array}{l}\text { 2-14 days } \\
\text { before death }\end{array}$ & $24.8 \pm 4.5$ & & & $24.7 \pm 4.5$ & & & $24.5 \pm 4.3$ & & & $24.2 \pm 4.1$ & & \\
\hline $\begin{array}{l}\text { Minimum Death } \\
\text { day }\end{array}$ & $2.9 \pm 3.7$ & 1.19 & 0.24 & $5.5 \pm 4.0$ & -2.16 & 0.03 & $4.5 \pm 4.0$ & -1.12 & 0.26 & $4.3 \pm 4.1$ & -1.00 & 0.32 \\
\hline $\begin{array}{l}2-14 \text { days } \\
\text { before death }\end{array}$ & $3.9 \pm 3.9$ & & & $3.7 \pm 3.8$ & & & $3.6 \pm 3.8$ & & & $3.5 \pm 3.8$ & & \\
\hline $\begin{array}{l}\text { Variance Death } \\
\text { day }\end{array}$ & $18.7 \pm 14.5$ & -3.36 & 0.003 & $7.2 \pm 4.2$ & 1.56 & 0.13 & $9.0 \pm 7.4$ & -0.13 & 0.90 & $10.3 \pm 11.2$ & -0.73 & 0.47 \\
\hline $\begin{array}{l}\text { 2-14 days } \\
\text { before death }\end{array}$ & $8.6 \pm 7.1$ & & & $8.8 \pm 7.3$ & & & $8.8 \pm 7.4$ & & & $8.5 \pm 6.6$ & & \\
\hline $\begin{array}{l}\text { Heart rate (per } \\
\text { minute) } \\
\text { Mean Death } \\
\text { day }\end{array}$ & $92.6 \pm 17.4$ & -2.90 & 0.004 & $88.4 \pm 16.8$ & -2.02 & 0.04 & $88.1 \pm 19.1$ & -2.09 & 0.04 & $84.8 \pm 18.0$ & -1.35 & 0.18 \\
\hline $\begin{array}{l}\text { 2-14 days } \\
\text { before death }\end{array}$ & $82.3 \pm 16.3$ & & & $81.4 \pm 15.9$ & & & $80.7 \pm 15.5$ & & & $80.1 \pm 15.1$ & & \\
\hline $\begin{array}{l}\text { Maximum } \\
\text { Death day }\end{array}$ & $120.8 \pm 22.3$ & -2.61 & 0.01 & $110.0 \pm 18.1$ & -0.15 & 0.88 & $108.7 \pm 19.4$ & 0.16 & 0.88 & $106.6 \pm 19.3$ & 0.68 & 0.49 \\
\hline $\begin{array}{l}\text { 2-14 days } \\
\text { before death }\end{array}$ & $109.4 \pm 20.2$ & & & $109.3 \pm 20.4$ & & & $109.4 \pm 20.6$ & & & $109.8 \pm 20.9$ & & \\
\hline $\begin{array}{l}\text { Minimum Death } \\
\text { day }\end{array}$ & $44.7 \pm 8.2$ & 4.03 & $<0001$ & $51.1 \pm 11.0$ & 0.53 & 0.60 & $51.5 \pm 12.2$ & 0.43 & 0.67 & $55.8 \pm 19.1$ & -0.79 & 0.44 \\
\hline $\begin{array}{l}\text { 2-14 days } \\
\text { before death }\end{array}$ & $52.5 \pm 14.1$ & & & $52.7 \pm 14.5$ & & & $52.9 \pm 14.8$ & & & $52.4 \pm 14.1$ & & \\
\hline $\begin{array}{l}\text { Variance Death } \\
\text { day }\end{array}$ & $187.1 \pm 220.8$ & -2.82 & 0.01 & $66.4 \pm 79.2$ & -0.55 & 0.58 & $49.5 \pm 44.0$ & 0.73 & 0.47 & $48.5 \pm 63.9$ & 0.86 & 0.39 \\
\hline $\begin{array}{l}2-14 \text { days } \\
\text { before death }\end{array}$ & $59.4 \pm 65.5$ & & & $58.6 \pm 63.8$ & & & $59.8 \pm 66.0$ & & & $61.5 \pm 66.4$ & & \\
\hline
\end{tabular}

*: compared each value of death day $(n=24)$ with 3-14 day before death days $(n=216)$ from a total of 240 patient-day data from 24 participating patients

**: t-test was used

$* * *$ SD: standard deviation

a: this number is 240 minuss the number of 24 patient death days' data

b: this number is 240 minus the number of 24 patient last 2-days' data

c: this number is 240 minus the number of 24 patient last 3-days' data

Table 4. Associations with respiratory rate/heart rate and death within the following 24 hours, 48 hours, 72 hours: Multivariate analysis* ( $\mathrm{n}=240$ patient days)

\begin{tabular}{|c|c|c|c|c|c|c|c|c|c|c|c|c|}
\hline & \multicolumn{4}{|c|}{$\begin{array}{c}\text { Death occurrence within } 0-24 \\
\text { hours }\end{array}$} & \multicolumn{4}{|c|}{$\begin{array}{c}\text { Death occurrence within } 0-48 \\
\text { hours }\end{array}$} & \multicolumn{4}{|c|}{$\begin{array}{l}\text { Death occurrence within 0- } \\
\text { 72_hours }\end{array}$} \\
\hline Parameter & $\begin{array}{l}\text { Odds } \\
\text { ratio }\end{array}$ & $95 \%$ & & P-value & $\begin{array}{l}\text { Odds } \\
\text { ratio }\end{array}$ & $95 \%$ & $\mathrm{I}^{* *}$ & P-value & $\begin{array}{l}\text { Odds } \\
\text { ratio }\end{array}$ & $95 \%$ & & P-value \\
\hline Intercept & 0.007 & 0.001 & 0.047 & $<.0001$ & 0.002 & 0.0003 & 0.019 & & 0.003 & 0.0003 & 0.038 & $<.0001$ \\
\hline Respir & 1.038 & 0.984 & 1.096 & 0.171 & 1.083 & 1.021 & 1.150 & 0.0084 & 1.100 & 1.008 & 1.120 & 0.033 \\
\hline Heart & 1.024 & 1.005 & 1.043 & 0.015 & 1.034 & 1.014 & 1.053 & 0.0005 & 1.031 & 1.013 & 1.050 & 0.001 \\
\hline
\end{tabular}


*: by repeated measures logistic regression analysis using a generalized estimating equation **: CI, confidence interval

\section{Figures}

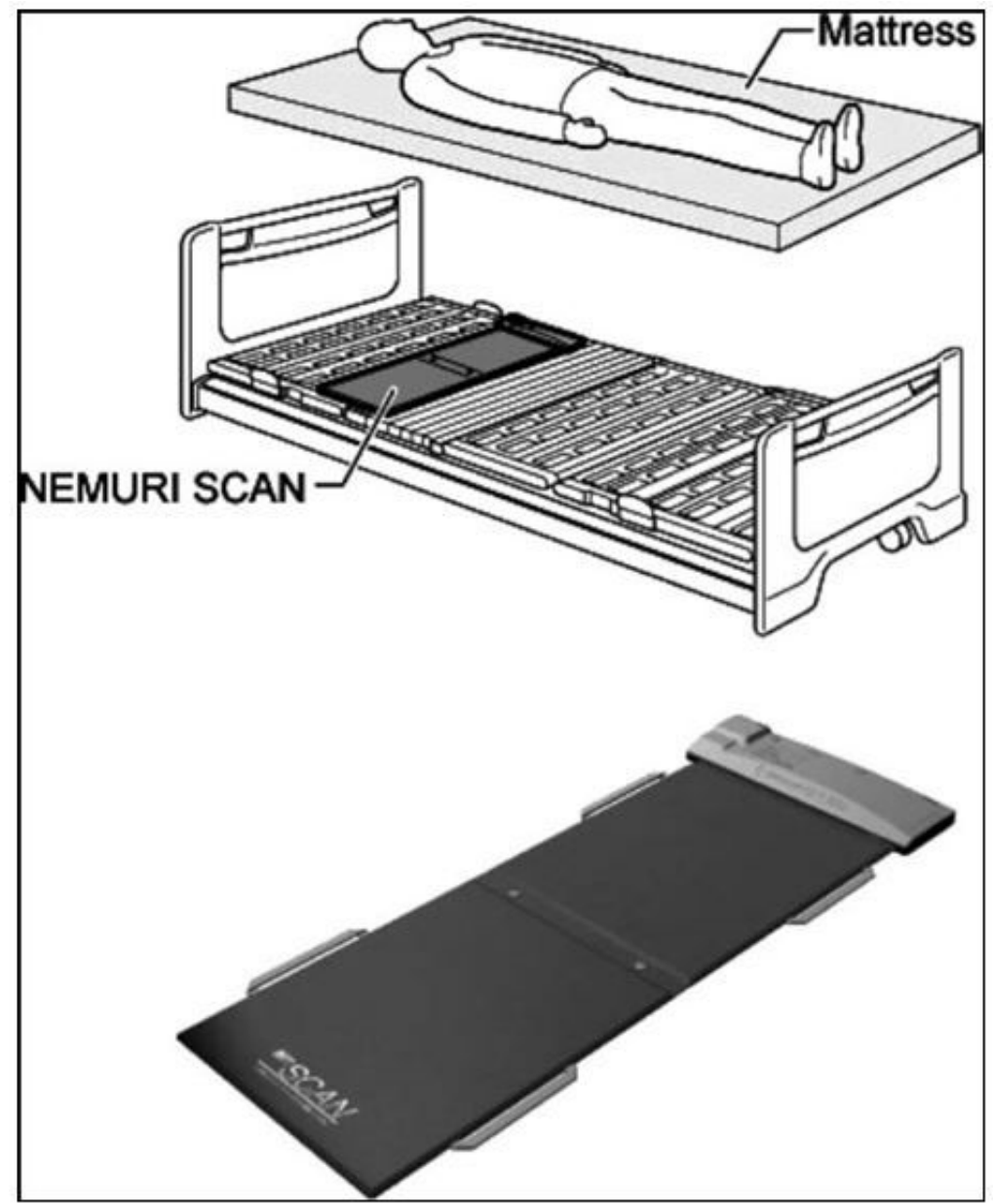

Nemuri SCAN (NN-1100; PARAMOUNT BED CO., LTD., Tokyo, Japan, Kogure, 2011)

Figure 1

Image of Nemuri SCAN

\section{Supplementary Files}

This is a list of supplementary files associated with this preprint. Click to download.

- Appendixcase12420210107.pdf

- coidisclosurefukui.pdf

- coidisclosurehatano.pdf

- coidisclosurehattori.pdf

- coidisclosurehigami.pdf

- coidisclosurehiguchi.pdf

- coidisclosureikuta.pdf

- coidisclosuremaeda.pdf 
- coidisclosuretanaka.pdf

- coidisclosureutsumi.pdf

- coidisclosureyamakawa.pdf 